\title{
Safety of Objects of the Urban Environment During Construction Work
}

\author{
Sergey Sinenko, Julia Yakupova*, and Hakim Satiadzhiev \\ Moscow State University of Civil Engineering, Yaroslavskoe shosse, 26, Moscow, 129337, Russia
}

\begin{abstract}
At the present time, the share of work related to the reconstruction and compaction of urban development is growing strongly. In this regard, there is growing interest in ensuring the safety requirements of urban environment objects during construction and reconstruction of buildings and structures. It is necessary to make the most rational use of existing infrastructures, preserving the architectural appearance of the urban environment. A characteristic feature of the construction and installation work is the need to combine the production of work and the operation of urban development facilities (residential, public, industrial buildings, as well as highways and footpaths). From the rationality of the choice of solutions to ensure the safety of these facilities, the expected effect of the reconstruction of urban development The limitation in this case is the need to ensure safe operating conditions for the objects of the urban environment. Therefore, the safety measures used in the production of construction and installation works must satisfy not only and not so much the requirements of labor protection, but also the requirements of environmental protection, the subject of which, in contrast to labor protection, is unskilled and unskilled and unprepared people. The purpose of this study is to develop an algorithm for accounting for labor safety in the construction industry and a system of protective equipment. The proposed system of means of protecting objects allows for the construction and reconstruction of buildings and structures during the consolidation or reconstruction of urban development. The choice of a rational complex of means and the order of their use in each specific case is determined depending on the characteristics of individual situations "the source of danger is a protected object of the urban environment" and their totality within the object. Organizational and technological solutions contained in the catalog allow solving this problem.
\end{abstract}

\section{Introduction}

Safety measures are an integral part of specific organizational and technological solutions, the composition and content of which are given in SP 48.13330.2019. Code of Practice. Organization of construction, SNiP 12-04-2002 "Labor safety in construction", part 1.2 and are developed in order to reflect the requirements and standards of labor safety $[2,3,4,10$, $12,13,14,15,16]$.

\footnotetext{
* Corresponding author: golub117@mail.ru
} 
Control of compliance with security requirements should be carried out at the stage when solutions are formed that meet all other requirements. This is because security requirements are generally the most stringent. In this case, first, an analysis of the developed solutions should be carried out in order to identify the potential conditions for the occurrence of injury. Next, it is necessary to develop appropriate measures to eliminate them.

In connection with the compaction of urban development, interest and requirements for ensuring the safety of work during the construction or reconstruction of buildings are increasing. Restricted areas for workers and restricted areas for outsiders should be identified. Hazardous areas include areas near places where goods are moved by a crane and near buildings under construction (reconstructed). [2] The boundaries of hazardous areas are determined by the area of operation of the crane and the outline of the building in which construction work is carried out, as well as the area of possible exit of objects, and are located within the construction area. The expansion of the site is impeded by the operated objects of the urban environment located next to it, the functioning of which, if located in hazardous areas, should be temporarily suspended. This is due to the eviction of people from residential buildings, the temporary cessation of the operation of public and industrial facilities, the blocking of highways and pedestrian crossings [3, 4].

The economic losses of society at market prices during the operation of urban environment facilities amount to $15-30 \%$ of the cost of construction and installation work. To avoid this, it is necessary to search for alternative solutions. However, as the state property acquires a specific owner, the urgency of this problem increases [17, 18]. To solve this problem, restrictions should be introduced during construction and installation work in such a way that the zones of permanent or temporary residence of people could not be within hazardous areas during the construction process. It is also necessary to replace the traditional technology of crane installation with a safer one, the use of protective equipment designed to limit the area of action of hazardous production factors, and to limit the area of operation of tower cranes, reduce the size of the area of the possible departure of objects in places where goods are moved by cranes and near buildings.[2].

\section{Materials and Methods}

According to the requirements of the current SNiP "Labor safety in construction", part 1, part 2, it is necessary to apply additional means of limiting (AML) the area of operation of tower cranes, allowing for forced limitation of the operation of crane mechanisms when moving goods in accordance with the situation on the site. If it is necessary to limit the departure area of the cargo, along with the AML, it is necessary to use load-gripping devices equipped with safety or safety devices, and install protective screens near buildings, excluding the possibility of objects flying into the area where people are located $[1,3]$.

A significant variety of construction conditions necessitates the development of protective equipment, different in their technical and economic indicators, information about which is contained in the catalog "Means of new technology and organizational and technological solutions to ensure safe operating conditions for urban environment objects located in the construction or reconstruction zone of buildings and structures" $[2,4,5]$

Control over the fulfillment of safety requirements during the operation of mechanisms for moving loads of a tower crane can be carried out using an electromechanical or electronic control system. Electromechanical systems are generally used to restrict the area of operation of tower cranes in relation to permanent restricted areas. However, electronic control systems are more versatile and can be used to limit situations of varying complexity, as well as to provide safe conditions for the joint operation of two or more tower cranes [2]. 
Safety measures are aimed at eliminating danger signs, envisaging measures to eliminate or limit the action of a hazardous production factor, as well as measures to eliminate the possibility of a person appearing in a hazardous area or restricting his access. If it is necessary to perform work in a hazardous area, measures should be taken to reduce the degree of exposure to a hazardous production factor. The structure of logical actions in the development of security solutions is shown in Fig. 1.

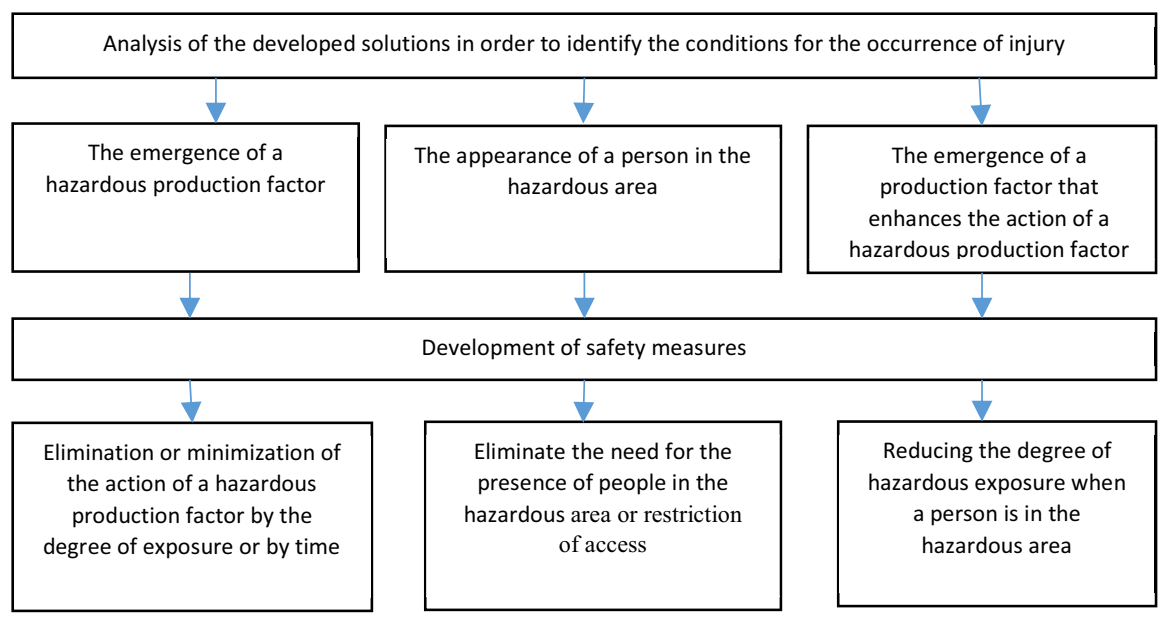

Fig. 1. Algorithm for accounting for labor safety in construction production

\section{Results}

Potentially hazardous production factors are: collapsing structures; collapsing soil; falling objects; overturning machines; stress on metal parts of machines, structures, equipment, usually without stress, etc.

The nature of the action of hazardous production factors determines the nature of protective measures for labor safety [1].

In the presence of constant hazardous production factors, protective measures for occupational safety are reduced to reducing the degree of hazardous effects of these factors by eliminating the possibility of a person appearing in the hazardous area or restricting his access there. For this, it is necessary, when developing organizational and production process solutions, to provide for the use of mechanization and automation tools to eliminate manual labor in hazardous areas, as well as the use of rational work methods that facilitate the transfer of time-consuming operations from hazardous areas. In the case when the implementation of these measures is not possible, you should restrict workers' access to hazardous areas [3]. For this, hazardous areas within the workplace must be fenced off. If it is necessary to perform work under conditions of constant hazardous production factors, it is necessary to develop schedules for the performance of combined work, providing for the limitation of the action of a hazardous production factor in time. If it is impossible to perform these actions when working in hazardous areas, it is necessary to use protective equipment, to carry out additional instructions for workers $[1,2,5,8,9]$.

If there is a possibility of the occurrence of potentially dangerous production factors, protective measures of safety measures should be aimed at preventing or limiting the likelihood of their occurrence. For this, it is necessary that the labor safety measures envisaged in the development of organizational and technological solutions correspond to the volumetric planning and structural solutions of buildings and structures and the conditions for the production of construction and installation and special works $[3,4,6,7]$. 
To increase the safety of work, it is necessary to establish areas that are dangerous for people, within which potentially dangerous production factors can act for a long period of time. These include places near the movement of goods by lifting and transport equipment, as well as buildings or structures under construction, reconstructed or demolished. It is prohibited to locate temporary buildings or structures in these areas, as well as workplaces associated with a long stay of people. Passages and driveways, if possible, should be arranged outside the hazardous areas [2, 3, 10, 12].

Considering that in our country these devices were not previously used, it was logical to start mastering them with simpler ones. The technical documentation of AML was developed for devices with electromechanical control for various tower cranes. These devices have a program block where you can set a certain number of combinations of restrictions of crane mechanisms and thus adapt the design of the devices to various situations at construction sites [2,3].

In order to increase the possible number of combinations, a hierarchical dependence of the regulation of the operation of the crane mechanisms limiters from each other is established; depending on the number of levels of the hierarchy, the design of the AML can be one-position or two-position.

At the top or the highest level of the hierarchy is the crane movement limiter on the crane runways. As a result of the analysis of possible situations arising at construction sites, it was found that at least three zones of crane operation are required. The zones of the crane operation are fixed by installing them on sleepers next to the crane tracks of the rulers, when the crane hits which the movement limiter is triggered. In this case, further movement of the crane occurs only if the parameters of the crane mechanisms (angle of rotation, boom reach, and lifting height) correspond to those permitted for this zone. Otherwise, crane movements are blocked [3].

At the second level of the hierarchy, there is a boom swing limiter, which in each work zone can be used to set a sector of prohibited work, and work sectors with limitation of boom reach and lifting height [2]. As an example, we can cite measures to ensure the safe production of work by cranes on different crane tracks (Table 1)

Table 1. Measures to ensure the safe performance of work by

\begin{tabular}{|c|l|l|}
\hline $\begin{array}{c}\text { No. } \\
\text { of shift }\end{array}$ & \multicolumn{1}{|c|}{ List of works } & \multicolumn{1}{c|}{ Occupational safety measures } \\
\hline 1 & $\begin{array}{l}\text { Unloading vehicles } \\
\text { from site } 3 \text { to an on- } \\
\text { site warehouse }\end{array}$ & $\begin{array}{l}\text { Installation of a dead-end stop to fix the position of the crane in parking } \\
\text { lot } 1 ; \text { limiting the angle of rotation of the crane boom to } 110^{\circ} \text { towards the } \\
\text { adjacent jib }\end{array}$ \\
\hline 2 & $\begin{array}{l}\text { Installation of } \\
\text { building structures }\end{array}$ & $\begin{array}{l}\text { Installation of a dead-end stop for fixing the crane in parking lot } 1 ; \text { limiting } \\
\text { the angle of rotation of the crane boom to } 110^{\circ} \text { towards the adjacent jib }\end{array}$ \\
\hline 3 & $\begin{array}{l}\text { Unloading vehicles } \\
\text { from site } 6 \text { to an on- } \\
\text { site warehouse }\end{array}$ & $\begin{array}{l}\text { Installation of a dead-end stop for fixing the crane in parking lot } 1 ; \text { limiting } \\
\text { the angle of rotation of the crane boom to } 110^{\circ} \text { towards the adjacent jib }\end{array}$ \\
\hline
\end{tabular}

The distance L between the service areas of the cranes is determined by the formula (1): 


$$
\mathrm{L}=\frac{A+B}{2}+S+1
$$

where A - the maximum dimensions of the cargo moved by the crane at the first grip;

$\mathrm{B}$ - the maximum dimensions of the cargo moved by the crane at the second grip;

$\mathrm{S}$ - the dimensions of the danger zone, determined depending on the height of the possible fall of the cargo moved by the crane (adopted according to SNiP 12-04-2002).

When choosing technological equipment, it is necessary that it corresponds to the conditions of work and provides an opportunity for high-performance work without injuries and accidents [2]. In this case, the main attention should be paid to the choice of paving means, the classification and general technical requirements of which are determined by GOST 24258-88 (in the current edition).

The development of electronic devices is envisaged, the principle of operation of which is fundamentally different from electromechanical. The control of the crane mechanisms limiters is carried out using an onboard computer, which, depending on the incoming information, determines the position of the load in space and, depending on the specified coordinates of the forbidden zones, regulates the operation of the crane mechanisms limiters [11].

Their use allows limiting the crane operation area with a sufficiently high degree of reliability, guaranteeing the fulfillment of the requirement to prohibit the crane from moving cargo in the areas where people are located. However, the fulfillment of this requirement may turn out to be insufficient when it becomes necessary to limit the size of the hazardous zone near the building under construction (reconstructed). In this case, if the device limits the area of operation of the crane to the outline of the building, the boundaries of the dangerous area are determined by the area of departure of falling objects. The dimensions of this zone depend on the height of falling objects and vary from $4 \mathrm{~m}$ at a fall height of $10 \mathrm{~m}$ to $15 \mathrm{~m}$ at a fall height of $120 \mathrm{~m}$. [2]

In a number of cases, operated objects of the urban environment are located near the building, for the protection of which from falling objects, the use of protective equipment is required, which are subdivided into natural, permanent, and artificial, specially installed. Bearing structures (walls and ceilings) of buildings and structures under construction and in operation can be used as natural means of protection, as artificial ones - protective screens and protective floor slabs, which are created by analogy with natural means of protection [3].

It is obvious that the use of existing structures of buildings and structures as protective means is preferable, however, these structures can perform protective functions only in certain cases. This applies primarily to the load-bearing walls of brick buildings, which are sufficiently reliable protection of people in the building from falling objects [3]. The protective properties of building floors are much lower. For example, typical ceilings used in housing and civil construction are destroyed when a 4-ton load falls from a height of 0.5 $\mathrm{m}$ and above. Therefore, the requirements of SNiP "Labor safety in construction", part 1, part 2 provide that "the operation of buildings and their individual parts located near buildings under construction or reconstructed is allowed provided that the floor slab of the upper floor of the building being operated is not in the area of possible falling objects near a building under construction (reconstructed)" [12].

In accordance with the requirements of occupational safety, protective equipment should be used in cases where natural protective equipment is absent or when it does not provide protective functions. At the same time, it is also obvious that the use of protective screens is more preferable in comparison with protective floor slabs, since vertical structures are designed not so much for the perception of the falling load as for keeping the structure from falling or limiting the falling zone. In any case, the loads transferred to the 
protective screens are not comparable to the loads transferred to the protective floor slabs $[2]$.

\section{Discussion}

Various designs of safety and protective screens have been developed. The presented designs of protective screens are not designed for the effect of shock loads from the fall of building structures moved by the crane, the mass of which reaches 8-10 tons. To prevent the fall of these structures in the system of applied protection measures "protective screen" one more element should be provided - a load-gripping device equipped with safety or protective devices.

The safety device protects the load moved by the crane from falling as a result of the rejection of products with defective mounting loops before lifting them to a height. What happens due to the impact on the product of an additional load exceeding the dynamic one and acting on the product during its movement by a crane. The device is combined with a load-gripping beam and allows testing automatically in the first phase of lifting the product. The load is supplied by a hydraulic spacer. The fall arrest device is designed to hold the structure in the event of a loop break. In comparison with the safety device, the belay device is simpler and more economical [3, 4].

The developed system of means for protecting urban environment objects allows monitoring the fulfillment of safety requirements for urban environment objects during the construction or reconstruction of buildings. The choice of the optimal set of means and measures to ensure safety in each specific case is determined depending on the characteristics of individual situations "the source of danger is the protected object of the urban environment" and their totality within the object.

\section{References}

1. Shirshikov B.F., Sinenko S.A., Zhadanovsky B.V. Organizational and process solutions for labor safety in work production projects. ASV Publishing House, 2015

2. Shesterikov Yu.A. Ensuring the safety of objects of the urban environment during the construction and reconstruction of buildings and structures // Results of scientific research: International scientific and practical conference (October 5, 2015, Yekaterinburg). /in 2 parts, part 2 - Ufa: AETERNA, 2015. 95-99

3. Sinenko S.A., Otsokov K.A. Improving safety during construction and installation work in buildings // Construction production. No. 2.2020, p.80-85.

4. GOST 12.0.003-2015, Occupational Safety Standards System. Dangerous and harmful working factors. Classification. Standartinform, 2016

5. GOST 12.4.009-83 Occupational Safety Standards System. Fire Fighting Equipment for Protection of Facilities. Main types. Dislocation and maintenance. Standards Publishing House, 2004

6. GOST 12.4.011-89 Occupational Safety Standards System. Means of protection of workers. General Requirements and Classification. Standards Publishing House, 2011

7. Ershov M.N., Lapidus A.A., Telichenko V.I. Book 7. Performance of roofing work and arrangement of protective coatings. ASV Publishing House, 2016

8. Zhadanovsky B.V., Sinenko S.A. Prospects for improving the technical level of production of concrete works in modern construction. Scientific Review. 2014. No. 92. P. 435-438.

9. Oleinik P.P., Shirshikov B.F. The composition of the sections of the organizational and process documentation and the requirements for their content. MSUCE Publishing house, $2013-63 \mathrm{p}$. 
10. Oleinik P.P., Brodsky V. I. Organization of construction production. Preparation and performance of construction and installation works. MSUCE Publishing house, 2014 $95 \mathrm{p}$.

11. Sanitation Standards and Regulations. SanPiN 2.2.3.1384-03 Hygienic requirements to the organization of construction operations and works. Federal Center for State Sanitary and Epidemiological Supervision of the Ministry of Health of Russia, 2010

12. Sinenko S.A., Mamochkin S.A., Zhadanovsky B.V. Foundations of the regulatory framework in construction. ASV Publishing House, 2016. 